\title{
BMJ Open Use of glucocorticoids during pregnancy and risk of attention-deficit/ hyperactivity disorder in offspring: a nationwide Danish cohort study
}

\author{
Kristina Laugesen, ${ }^{1}$ Anna Byrjalsen, ${ }^{2}$ Trine Frøslev, ${ }^{1}$ Morten S Olsen, ${ }^{1}$ \\ Henrik Toft Sørensen ${ }^{1}$
}

To cite: Laugesen $\mathrm{K}$, Byrjalsen A, Frøslev T, et al. Use of glucocorticoids during pregnancy and risk of attentiondeficit/hyperactivity disorder in offspring: a nationwide Danish cohort study. BMJ Open 2017;7:e016825. doi:10.1136/ bmjopen-2017-016825

- Prepublication history and additional material for this paper are available online. To view please visit the journal (http:// dx.doi.org/10.1136/bmjopen2017-016825).

$\mathrm{KL}$ and $\mathrm{AB}$ are shared first authorship.

Received 13 March 2017 Revised 5 July 2017 Accepted 16 August 2017

CrossMark

${ }^{1}$ Department of Clinical Epidemiology, Aarhus University Hospital, Aarhus, Denmark ${ }^{2}$ Department of Clinical Genetics, Rigshospitalet, Copenhagen, Denmark

Correspondence to Kristina Laugesen; kristina.laugesen@clin.au.dk

\section{ABSTRACT}

Objective Prenatal exposure to excess endogenous glucocorticoid (GC) has been linked to attention-deficit/ hyperactivity disorder (ADHD). We investigated whether prenatal exposure to exogenous GC is associated with ADHD.

Design Nationwide cohort study.

Setting A cohort of 875996 singletons born alive between 1996 and 2009 in Denmark. Data were obtained from national registries.

Exposures We identified children exposed prenatally to GCs, children unexposed prenatally and born to maternal former users, and children unexposed and born to maternal never users.

Main outcome measures We compared ADHD risk in children prenatally exposed to GCs and in children of former GC users with risk in unexposed children of never users. We computed cumulative incidence at 10 years of age and adjusted HRs (aHRs). In addition, we compared exposed children with unexposed siblings in a sibling design.

Results We identified 875996 children, among whom 5319 were prenatally exposed to systemic GCs and 36780 to local/inhaled GCs. Cumulative incidences of ADHD at 10 years of age were $2.65 \%$ in prenatally exposed children and $2.03 \%$ in unexposed children of never users. At the general population level, prenatal exposure was associated with ADHD compared with unexposed, with aHR of $1.43(95 \% \mathrm{Cl} 1.24$ to 1.65) for systemic exposure and $1.23(95 \% \mathrm{Cl} 1.15$ to 1.31) for local/inhaled exposure. However, our former user analysis (aHR of $1.25(95 \% \mathrm{Cl}$ 1.20 to 1.29)) and sibling design (aHR of $1.03(95 \% \mathrm{Cl}$ 0.87 to 1.20$)$ ) indicated that these findings were due to confounding.

Conclusion This study provides no evidence of a causal association between prenatal exposure to GCs and risk of ADHD.

\section{INTRODUCTION}

Glucocorticoids (GCs) are anti-inflammatory agents used commonly since the 1950 s to treat asthma, rheumatic diseases and other autoimmune diseases. ${ }^{1}$ GC (mainly cortisol) is also synthesised endogenously in humans.

\section{Strengths and limitations of this study}

- This study was a large nationwide population-based study with long and virtually complete $(\approx 95 \%)$ follow-up.

- We conducted a sibling analysis that allowed us to adjust for family-related factors, such as genetic and socioeconomic factors.

- We were limited by our lack of data on actual maternal use of glucocorticoids, as we used prescription redemption as a proxy for this information. This could have led to misclassification of exposure status.

- Attention-deficit/hyperactivity disorder is diagnosed based on criteria evaluating, for example, impulsiveness, inattention and hyperactivity. Assessment of these behaviours can be prone to interindividual judgement among physicians.

Besides, having effects on the inflammatory system cortisol plays an important role in maintaining cardiovascular and metabolic homoeostasis especially during physiological or psychological stress. Hence, cortisol is also known as a stress hormone. ${ }^{2}$ Exogenous GCs used in treatment regimens (both systemic and local formulations) are absorbed to the blood stream. Thus, exogenous GCs have the potential to affect human systems in similar ways as endogenous cortisol. ${ }^{3}$

GCs (both exogenous and endogenous) are known to cross the placental barrier and thus have the potential to affect fetal development. ${ }^{4}$ Both animal and human studies have found that prenatal GC exposure can cause behavioural changes and increased anxiety levels in offspring. ${ }^{5-8}$ A suggested explanation is 'fetal programming', a concept that describes the fetus' physiological adaptation to the characteristics of the intrauterine environment. ${ }^{9}$ It is hypothesised that this environment has long-lasting effects on a child's health. $^{10}$ 


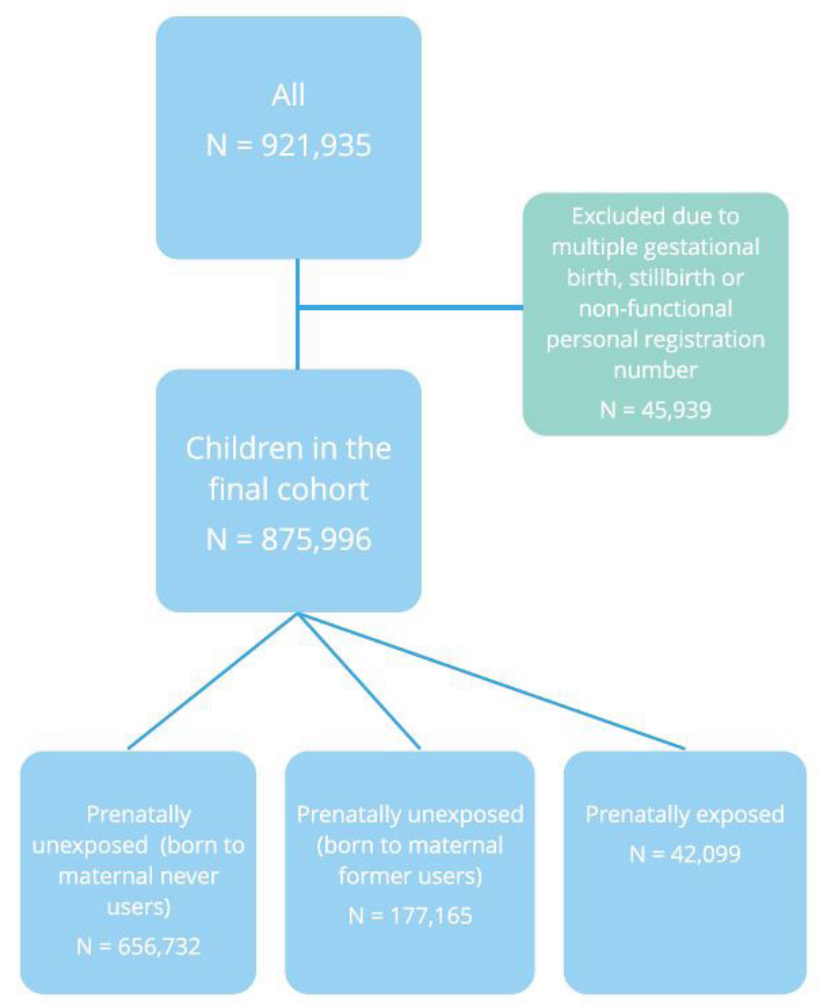

Figure 1 Children identified in the Danish Medical Birth Registry (1996-2009).

Attention-deficit/hyperactivity disorder (ADHD) is a common neurodevelopmental disorder characterised by impulsiveness, inattention and hyperactivity. The incidence of childhood ADHD is increasing, with the current worldwide prevalence estimated at approximately $5 \% .^{11}$ An important risk factor for ADHD is heritability. ${ }^{12}$ Other proposed risk factors include preterm birth and prenatal exposure to smoking or alcohol. ${ }^{13-16}$ However, knowledge on causal mechanisms underlying the development of ADHD still needs more investigation. There is little evidence available on the risk of ADHD following prenatal exposure to GCs. However, one study reported an association between maternal stress during pregnancy and increased risk of ADHD in offspring, possibly due to a stress-related increase in cortisol during pregnancy. ${ }^{17}$ Few studies of women exposed to GCs because of impending preterm birth found an increased risk of adverse neuropsychiatric outcomes (eg, ADHD) among their offspring. However, preterm delivery in itself increases the risk of ADHD and other adverse outcomes in children. ${ }^{18} 19$

Some inflammatory diseases treated with GCs are also risk factors for adverse birth outcomes. For instance, IBD increases the risk of stillbirth, growth restriction and preterm delivery, and this risk increases if the disease is poorly managed. ${ }^{20}$ Cessation of GC treatment during pregnancy thus is not possible for women with most chronic inflammatory diseases. This underscores the need for a better understanding of potential adverse

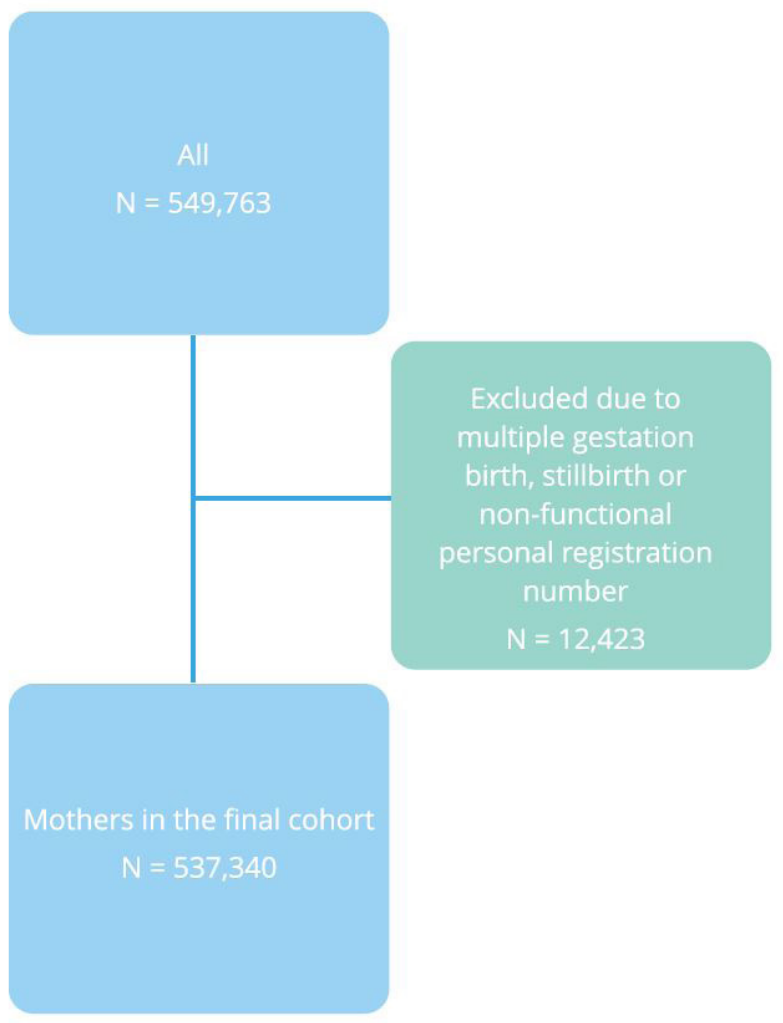

Figure 2 Mothers identified in the Danish Medical Birth Registry (1996-2009).

neurodevelopmental outcomes after prenatal exposure to GCs.

Therefore, we conducted a cohort study on use of GCs during pregnancy and risk of ADHD in offspring.

\section{METHODS}

\section{Setting}

We conducted this cohort study in Denmark, which has 5.6 million inhabitants and approximately 65000 births annually. The Danish healthcare system provides tax-supported health services to all residents, guaranteeing access to primary and secondary care free of charge. A unique central personal registration number (the civil registration number) is assigned to all Danish residents at birth by the Civil Registration System (CRS) ${ }^{21}$ It is used in registries to record use of health services, allowing continuous population surveillance and permitting accurate and unambiguous linkage of information among relevant registries at the individual level.

\section{Study population and design}

We used the Danish Medical Birth Registry ${ }^{22}$ to identify a cohort of all singletons born alive in Denmark from 1 January 1996 until 31 December 2009 (figure 1 and figure 2). The Danish Medical Birth Registry contains computerised records of all deliveries in Denmark since 1973. Each record includes the civil registration number of the mother, father and newborn, as well as multiple variables describing the delivery, the newborn and the 
Table 1 Distribution of 42099 prenatally exposed children according to time of exposure and type of administration

\begin{tabular}{lc}
\hline & $\mathbf{n ~ ( \% )}$ \\
\hline All & 42099 \\
\hline $\begin{array}{l}\text { According to administration form } \\
\quad \text { All systemic treatment }\end{array}$ & $5319(12.6)$ \\
$\begin{array}{l}\text { Systemic, low dose (1 redeemed } \\
\text { prescription) }\end{array}$ & $3797(9.0)$ \\
$\begin{array}{l}\text { Systemic, high dose ( } \geq 2 \text { redeemed } \\
\text { prescriptions) }\end{array}$ & $1522(3.6)$ \\
$\quad \begin{array}{l}\text { Local/inhaled } \\
\text { According to time of first exposure }\end{array}$ & $36780(87.4)$ \\
\hline $\begin{array}{l}\text { First-trimester exposure } \\
\text { Second-trimester and third-trimester } \\
\text { exposure } \\
\quad \leq 30 \text { days prior to pregnancy }\end{array}$ & $11702(27.8)$ \\
\hline
\end{tabular}

mother. The midwives or physicians overseeing the deliveries collect the data. Siblings born to the same mother were identified through the CRS. Thus it was possible to identify a sibling comparison cohort that was highly suitable for optimising adjustment for important potential family-related and genetic confounders. We also established a general population cohort to allow comparisons with unexposed children of never users.

\section{Maternal GC use}

Prenatal exposure to GCs was defined as maternal redemption of a prescription for at least one systemic GC and/or two redeemed prescriptions for a local GC or two redeemed prescriptions for an inhaled GC 30 days prior to or at any time during pregnancy. Prescriptions were identified through the Danish National Prescription Registry. ${ }^{23}$ Since January 1994, this registry has recorded information on all prescriptions redeemed in Denmark, including the patient's civil registration number, the medication classification code (the Anatomical Therapeutic Chemical classification system of WHO) and the date of dispensing. Most local and all inhaled and systemic GCs, as well as all ADHD medications, are available only by prescription in Denmark. Pregnancy was defined as starting from the first day of the last menstrual period, according to the definition used by the Danish Medical Birth Registry. First-trimester exposure was defined as redemption of a prescription by the mother during the period 30 days prior to start of pregnancy up to 12 weeks after start of pregnancy; second-trimester and third-trimester exposure was defined as prescription redemption during the remainder of the pregnancy. ${ }^{24}$ If the mother redeemed more than one prescription during pregnancy, the date of the first redemption for systemic GCs or the date of the second redemption for local/inhaled GCs was used to determine the time of first exposure. We defined maternal former users of GCs as women who had redeemed a prescription for one systemic GC and/or for two local or inhaled GCs up to 30 days prior to pregnancy. Never users were women who had never redeemed a prescription for GCs from 1994 and until birth. ${ }^{25}$

\section{ATTENTION-DEFICIT/HYPERACTIVITY DISORDER}

ADHD in offspring was defined as a diagnosis of ADHD by a physician or by redemption of a prescription for ADHD medication. We used the Danish Psychiatric Registry ${ }^{26}$ and the Danish National Patient Registry (DNPR) ${ }^{27}$ to identify children in the study population who had an inpatient or outpatient hospital diagnosis of ADHD. The Danish Psychiatric Registry contains computerised data on all admissions to psychiatric hospitals since 1969 and on outpatient contacts since 1995. The DNPR has tracked all inpatient stays at Danish public hospitals since 1977, and outpatient clinic and emergency room visits at all public hospitals since 1995. Data recorded in the DNPR and the Danish Psychiatric Registry include the patient's civil registration number, dates of admission and discharge or outpatient visit dates, and up to 20 discharge diagnoses for each contact, classified according to the Eighth Revision of the International Classification of Diseases until 1994 and the 10th Revision thereafter. Diagnosis and treatment of ADHD are also handled by psychiatrists in private practice. These patients are not recorded in the Danish Psychiatric Registry or the DNPR. Therefore, to ensure completeness, we defined ADHD as either a diagnosis of ADHD or redemption of a prescription for ADHD medication. Information on prescription rede mption was obtained from the Danish National Prescription Registry.

\section{Covariates}

We obtained information on several risk factors for ADHD in offspring. This included information from the Danish Psychiatric Registry on maternal and paternal psychiatric diagnoses any time before pregnancy, information from the DNPR and the Danish National Prescription Registry on maternal diabetes and infectious diseases during pregnancy, and information from the Danish Medical Birth Registry on maternal age at birth, sex of the child and maternal smoking during pregnancy. As maternal body mass index was available only from 2004 on, and marital status was incompletely registered after 2006, body mass index and marital status were included as covariates only in separate subanalyses. Since the prevalence of both GC use and ADHD increased between 1996 and 2014, we also adjusted for calendar year of birth. We also obtained information from the Danish Medical Birth Registry on the following characteristics of newborns: gestational age at birth, birth weight, mode of delivery, birth order and 5 min Apgar score. The characteristics of the newborn were investigated as possible intermediators in the pathway from prenatal GC exposure to ADHD development and therefore only investigated for descriptive purposes and not included in the regression analyses. 


\section{Statistical analyses}

All statistical analyses were performed using SAS (V.9.4). The study was approved by the Danish Data Protection Agency (record no 2011-41-6465). Codes used to define study variables are provided in the online supplementary appendices 1 and 2.

Children were followed from date of birth until the date of an ADHD diagnosis, redemption of a prescription for an ADHD medication, emigration, death or the end of follow-up on 31 December 2014, whichever came first.

General population comparison cohort

We computed cumulative incidences of ADHD at 10 years of age in children exposed prenatally to GCs, in children of maternal former users and unexposed children of never users. Then, we compared children exposed prenatally to GCs and children of maternal former users with the unexposed children of never users. Using Cox proportional-hazards regression, we computed crude and adjusted HRs (aHRs) with 95\% CIs as measures of relative risk. The assumption of proportional hazards was graphically verified.

We performed subanalyses: first, we disaggregated GCs as local/inhaled or systemic. Second, we disaggregated systemic exposure as one redeemed prescription or two or more redeemed prescriptions.

Table 2 Characteristics of 875996 singleton births in Denmark in 1996-2009, according to maternal use of glucocorticoids during pregnancy

Prenatally exposed, $\mathbf{n}(\%)$ users, $\mathbf{n}(\%)$

$\begin{array}{ll}\begin{array}{l}\text { Prenatally unexposed and } \\ \text { born to maternal never } \\ \text { users, } \mathbf{n}(\%)\end{array} & \begin{array}{l}\text { Prenatally unexposed and } \\ \text { born to maternal former }\end{array} \\ \text { users, } \mathbf{n}(\%)\end{array}$

\begin{tabular}{|c|c|c|c|}
\hline All & 42099 & 656732 & 177165 \\
\hline \multicolumn{4}{|l|}{ Birth year } \\
\hline 1996-2000 & $13416(31.8)$ & $273713(41.7)$ & $34256(19.3)$ \\
\hline 2001-2005 & 14647 (34.8) & $223783(34.0)$ & 69991 (39.5) \\
\hline 2006-2009 & $14036(33.3)$ & $159236(24.2)$ & $72918(41.1)$ \\
\hline \multicolumn{4}{|l|}{ Sex } \\
\hline Boy & 21875 (52.0) & 336827 (51.3) & $90955(51.3)$ \\
\hline Girl & $20224(48.0)$ & $319905(48.7)$ & $86210(48.7)$ \\
\hline \multicolumn{4}{|l|}{ Birth order } \\
\hline 1 & $16326(38.8)$ & $297280(45.3)$ & $62592(35.3)$ \\
\hline 2 & $16464(39.1)$ & $239674(36.5)$ & $70810(40.0)$ \\
\hline$\geq 3$ & 9309 (22.1) & $119778(18.2)$ & $43763(24.7)$ \\
\hline \multicolumn{4}{|l|}{ Birth weight } \\
\hline$<2000 \mathrm{~g}$ & $282(0.7)$ & $4692(0.7)$ & $1222(0.7)$ \\
\hline $2000-2499 \mathrm{~g}$ & $960(2.3)$ & $14.405(2.2)$ & $3848(2,2)$ \\
\hline $2500-2999 \mathrm{~g}$ & $4132(9.8)$ & $67642(10.3)$ & $17425(9.8)$ \\
\hline $3000-5500 \mathrm{~g}$ & 36244 (86.1) & $560481(85.3)$ & 152627 (86.2) \\
\hline Missing, very low or very high & $481(1.1)$ & $9512(1.5)$ & $2043(1.2)$ \\
\hline \multicolumn{4}{|l|}{ Apgar score } \\
\hline$\leq 7$ & $539(1.3)$ & $8391(1.3)$ & $2179(1.2)$ \\
\hline$>7$ & $41158(97.8)$ & $640191(97.5)$ & $173423(97.9)$ \\
\hline Missing & $402(1.0)$ & $8150(1.2)$ & $1563(0.9)$ \\
\hline \multicolumn{4}{|l|}{ Gestational age } \\
\hline$<30$ weeks & $127(0.3)$ & $2225(0.3)$ & $648(0.4)$ \\
\hline 30-36 weeks & $1846(4.4)$ & $28964(4.4)$ & $8462(4.8)$ \\
\hline $37-41$ weeks & 36690 (87.2) & $569898(86.8)$ & 155774 (87.9) \\
\hline$>41$ weeks & $3223(7.7)$ & $50699(7.7)$ & $11550(6.5)$ \\
\hline Very low or missing & $213(0.5)$ & $4946(0.8)$ & $731(0.4)$ \\
\hline \multicolumn{4}{|l|}{ Mode of delivery } \\
\hline Vaginal & $33180(78.8)$ & $547163(83.3)$ & $140626(79.4)$ \\
\hline Caesarean & 8919 (21.2) & $109569(16.7)$ & 36539 (20.6) \\
\hline
\end{tabular}




\section{Sibling comparison cohort}

To control for family-related factors such as genetics and socioeconomic status, we conducted a sibling-matched analysis. ${ }^{28}$ We used stratified Cox regression with a separate stratum for each family identified by the mother's personal registration number. In this analysis, each family has its own baseline rate function reflecting the family's shared genetic and social factors. The stratified Cox regression model is an extension of the paired binomial model, taking into account the differences in follow-up time. Hence, only siblings discordant for exposure and ADHD contributed with information to the estimates. We adjusted for calendar year of birth, sex of the child, birth order, maternal smoking status and maternal infectious diseases during pregnancy.

In the general population analyses as well as in the sibling design, we accounted for clustering of observations in computation of CIs, as some children were born by the same mother.

\section{RESULTS}

We identified 875996 singletons born alive between 1996 and 2009, of whom 42099 (4.8\%) were exposed to GCs prenatally, 177165 (20.2\%) were born to maternal former users of GCs and $656732(75.0 \%)$ were born to maternal never users. Table 1 presents the distribution of exposure according to trimester and form of GC administration.

In the sibling analysis, we identified 608643 children born by 269987 mothers. Of these, 44660 were discordant for exposure (20162 prenatally exposed). Only 2246 children contributed informative to the estimates.

\section{Birth outcomes}

The sex distribution was the same for prenatally exposed and unexposed children. Children exposed prenatally to GCs and unexposed children born to never users had the same prevalence of low birth weight (3.0\% vs $2.9 \%)$, low 5 min Apgar score (1.3\% vs 1.3\%) and the same prevalence of premature birth (4.7\% vs $4.8 \%$ ). Caesarean section was performed more often in mothers of prenatally exposed children compared with unexposed children born to never users (21.2\% vs $16.7 \%)$ (table 2$)$.

\section{Maternal and paternal characteristics}

Age at delivery was higher among maternal users of GCs than among never users. Compared with maternal never users, maternal users of GCs were more likely to have a prior diagnosis of psychiatric illness $(9.4 \%$ vs $6.6 \%)$, inflammatory bowel disease $(2.7 \%$ vs $0.3 \%)$, asthma (15.9\% vs $0.7 \%)$, other autoimmune disease (4.5\% vs $1.4 \%)$ and type 1 and 2 diabetes (1.7\% vs $1.0 \%)$. There was no difference in prior psychiatric illness in fathers (table 3 ).

\section{Risk estimates}

Cumulative incidences of ADHD at 10 years of age were $2.65 \%$ (CI $2.56 \%$ to $2.74 \%$ ) in prenatally exposed children, $2.65 \%$ (95\% CI $2.56 \%$ to $2.74 \%$ ) in children of former users and $2.03 \%$ (95\% CI $2.00 \%$ to $2.07 \%$ ) in unexposed children of never users. When we compared prenatally exposed children to unexposed children born to never users, we observed an elevated risk of ADHD in exposed children ( $\mathrm{aHR}=1.43$ (95\% CI 1.24 to 1.65$)$ for systemic GCs and aHR=1.23 (95\% CI 1.15 to 1.31) for local/inhaled GCs.) We did not observe a substantial variation of the HRs according to dose or timing of exposure. Unexposed children born to former GC users had an elevated risk of ADHD (aHR=1.25 (95\% CI 1.20 to 1.29)) (table 4). When including BMI and marital status in sub analyses the estimates did not change substantially. The aHR in the sibling analysis was 1.03 (95\% CI 0.87 to 1.20$)$ (table 5).

\section{DISCUSSION}

Our analyses based on a general population comparison cohort showed an association between prenatal exposure to GCs and ADHD. However, the sibling design did not support a causal association. This observation strongly indicates the presence of unmeasured confounding in the comparison with the general population cohort. Further, this is underlined in the general population comparison cohort by unexposed children born to former GC users had an elevated risk of ADHD.

Previous studies examining the association between stress during pregnancy and the development of ADHD in offspring suggested that endogenous GC plays a role in ADHD development, and some studies reported an association between prenatal exposure to GCs and the development of ADHD. ${ }^{18}{ }^{19}$ However, the children were burdened by a number of comorbidities associated with preterm birth and thus are not comparable with our cohort.

The strengths of our study include its large study population with long and virtually complete $(\approx 95 \%)$ follow-up and use of population-based registries. Thus, selection biases were virtually eliminated. As well, the sibling design allowed us to adjust for shared confounders among the siblings. These could be family-related factors, such as genetic and socioeconomic factors, as siblings are thought to grow up in the same environment and share their genetic background. Genetic factors could be a potentially strong confounder in the general population comparison cohort as associations between autoimmune disorders and psychiatric disorders do exist. ${ }^{29}$ However, the sibling design also has limitations. First, the analysis reduces the size of the study population, since only sibling pairs discordant for both exposure and outcome are informative and contribute to the effect estimate. These births may represent a selected part of the population. Moreover, the analysis has lower statistical power than the conventional cohort study design. Second, in regards to non-shared confounders, the exposure-discordant sibling pairs are likely to differ more from each other than two randomly selected persons from the same population 
Table 3 Maternal and paternal baseline characteristics of 875996 singleton births in Denmark in 1996-2009, according to maternal use of glucocorticoids (GCs) during pregnancy

\begin{tabular}{|c|c|c|c|}
\hline & $\begin{array}{l}\text { Maternal users of GCs, } \\
\mathrm{n}(\%)\end{array}$ & $\begin{array}{l}\text { Maternal never users of } \\
\text { GCs, } n(\%)\end{array}$ & $\begin{array}{l}\text { Maternal former users of } \\
\text { GCs, } n(\%)\end{array}$ \\
\hline All & 42099 & 656732 & 177165 \\
\hline \multicolumn{4}{|l|}{ Age at delivery (years) } \\
\hline$<25$ & $3376(8.0)$ & $101264(15.4)$ & $16709(9.4)$ \\
\hline $25-29$ & $12690(30.1)$ & $235419(35.9)$ & $56297(31.8)$ \\
\hline $30-34$ & $16672(39.6)$ & $223127(34.0)$ & $68364(38.6)$ \\
\hline $35-39$ & 7947 (18.9) & $83615(12.7)$ & $30505(17.2)$ \\
\hline$>40$ & $1414(3.4)$ & $13307(2.0)$ & $5290(3.0)$ \\
\hline \multicolumn{4}{|l|}{ Smoking during pregnancy } \\
\hline No & 33515 (79.6) & $502326(76.5)$ & $141429(79.8)$ \\
\hline $1-10$ cigarettes/day & $5223(12.4)$ & $97302(14.8)$ & $21647(12.2)$ \\
\hline 11-20 cigarettes/day & $1593(3.8)$ & $27333(4.2)$ & $7393(4.2)$ \\
\hline$>20$ cigarettes/day & $248(0.6)$ & $3791(0.6)$ & $1088(0.6)$ \\
\hline Missing & $1520(3.6)$ & $25980(4.0)$ & $5608(3.2)$ \\
\hline $\begin{array}{l}\text { Maternal psychiatric illness (ADHD } \\
\text { not included) }\end{array}$ & $3950(9.4)$ & $43284(6.6)$ & $17930(10.1)$ \\
\hline Maternal ADHD & $39(0.09)$ & $292(0.04)$ & $163(0.09)$ \\
\hline $\begin{array}{l}\text { Paternal psychiatric illness (ADHD } \\
\text { not included) }\end{array}$ & $2370(5.6)$ & $36492(5.6)$ & $11515(6.5)$ \\
\hline Paternal ADHD & $51(0.12)$ & $588(0.09)$ & $253(0.14)$ \\
\hline \multicolumn{4}{|l|}{ Maternal diseases } \\
\hline Diabetes & $702(1.7)$ & $6555(1.0)$ & $3013(1.7)$ \\
\hline Asthma & $6674(15.9)$ & $4820(0.7)$ & $10093(5.7)$ \\
\hline COPD & $405(1.0)$ & $986(0.2)$ & $800(0.5)$ \\
\hline IBD & $1128(2.7)$ & $1993(0.3)$ & $3073(1.7)$ \\
\hline Other autoimmune diseases & $1707(4.1)$ & $8998(1.4)$ & $5265(3.0)$ \\
\hline Infections during pregnancy & $19026(45.2)$ & $210747(32.1)$ & $67977(38.4)$ \\
\hline \multicolumn{4}{|l|}{ Maternal BMI } \\
\hline Low & $730(1.7)$ & $12374(1.9)$ & $4244(2.4)$ \\
\hline Normal & $11466(27.2)$ & $143008(21.8)$ & $58237(32.9)$ \\
\hline Overweight & $4174(9.9)$ & $45727(7.0)$ & $21515(12.1)$ \\
\hline Obese and severely obese & $2496(6.0)$ & $24588(3.7)$ & $12795(7.2)$ \\
\hline No BMI (before 2004) & 21840 (51.9) & $411956(62.7)$ & $72933(41.2)$ \\
\hline Missing or very low & $1393(3.3)$ & $19079(2.9)$ & $7441(4.2)$ \\
\hline \multicolumn{4}{|l|}{ Maternal marital status } \\
\hline Married & 17941 (42.6) & $290268(44.2)$ & $69011(39)$ \\
\hline Not married & 13422 (31.9) & 248501 (37.8) & $52581(30)$ \\
\hline $\begin{array}{l}\text { Missing/not registered from } 2007 \\
\text { and onwards }\end{array}$ & $10736(25.5)$ & $117963(18)$ & $55573(31.4)$ \\
\hline
\end{tabular}

Low BMI: $15-18.4 \mathrm{~kg} / \mathrm{m}^{2}$; normal BMl: $18.5-24.9 \mathrm{~kg} / \mathrm{m}^{2}$; overweight: $25-29.9 \mathrm{~kg} / \mathrm{m}^{2}$; obese and severely obese: $\geq 30 \mathrm{~kg} / \mathrm{m}^{2}$. Data on BMl only available starting in 2004.

${ }^{*} \mathrm{~N}=129$ with missing information before 2007. This number is not further outlined in the table due to legislations.

ADHD, Attention-deficit/hyperactivity disorder; BMI, body mass index; COPD, chronic obstructive pulmonary disease; IBD, inflammatory bowel disease. 
Table 4 Crude and adjusted HRs (aHRs) and 95\% Cls for attention-deficit/hyperactivity disorder (ADHD), comparing prenatally exposed children and unexposed children born to maternal former users, to unexposed children born to maternal never users

$\begin{array}{ll}\begin{array}{l}\text { Children } \\ \text { classified }\end{array} & \begin{array}{l}\text { Children not } \\ \text { classified } \\ \text { with ADHD, } \mathrm{n}\end{array} \\ \text { with ADHD, } \mathrm{n}\end{array}$

\begin{tabular}{|c|c|c|c|c|}
\hline Unexposed & 22936 & 810961 & 1.00 (reference) & 1.00 (reference) \\
\hline Exposed to systemic, inhaled or topical GCs & 1263 & 40836 & 1.23 (1.16 to 1.30$)$ & 1.26 (1.18 to 1.33$)$ \\
\hline \multicolumn{5}{|l|}{ According to administration and dose } \\
\hline Exposed systemic GCs & 194 & 5125 & 1.53 (1.33 to 1.76$)$ & $1.43(1.24$ to 1.65$)$ \\
\hline Exposed systemic GCs low dose (1 prescription) & 136 & 3661 & $1.47(1.24$ to 1.73$)$ & 1.37 (1.15 to 1.62$)$ \\
\hline $\begin{array}{l}\text { Exposed systemic GCs high dose ( } \geq 2 \\
\text { prescriptions) }\end{array}$ & 58 & 1464 & 1.68 (1.29 to 2.19$)$ & 1.60 (1.23 to 2.08$)$ \\
\hline Exposed local or inhaled GCs & 1069 & 35711 & 1.18 (1.11 to 1.26$)$ & $1.23(1.15$ to 1.31$)$ \\
\hline \multicolumn{5}{|l|}{ According to trimester of exposure } \\
\hline First trimester & 469 & 14146 & $1.30(1.17$ to 1.44$)$ & $1.32(1.19$ to 1.47$)$ \\
\hline Second or third trimester & 794 & 26690 & 1.19 (1.11 to 1.28$)$ & $1.23(1.14$ to 1.32$)$ \\
\hline Former users (unexposed during pregnancy) & 4574 & 172591 & 1.27 (1.23 to 1.31$)$ & 1.25 (1.20 to 1.29$)$ \\
\hline
\end{tabular}

*Adjusted for sex of the child, calendar year of birth, birth order, maternal age at birth, maternal smoking status, maternal psychiatric diagnoses, paternal psychiatric diagnoses and maternal diabetes or infectious disease during pregnancy.

GCs, glucocorticoids.

having the same exposure levels. This can potentially increase the effect of the non-shared confounders. Third, misclassification will lead to attenuation of the estimates. ${ }^{30}$ Nevertheless, our findings of no association in the sibling design is supported by the results from our former user analysis based on the general population comparison cohort. In addition, we found a slightly higher HR for systemic high dose GC than systemic low dose GC exposure when we compared prenatally exposed children to unexposed children born to never users in our general population comparison cohort. The higher HR found in the high dose category could be explained by confounding by severity of underlying disease, thus, supporting our conclusion.

We were limited by our lack of data on actual maternal use of GCs, as we used prescription redemption as a proxy for this information. This could have led to misclassification of exposure status. For children classified as prenatally exposed, we cannot be sure that women who redeemed a prescription 30 days before or during pregnancy actually used the GCs during pregnancy. Also, GCs redeemed prior to pregnancy could have been stored and later used during pregnancy. Furthermore, the
Danish National Prescription Registry has only recorded information since 1994 and some women categorised as never users may have used GCs before that year. Misclassification of exposure would bias our results towards no association. ${ }^{31}$

While the majority of children with ADHD are diagnosed in outpatient clinics at public hospitals, some are diagnosed by private psychiatrists and thus not included in the DNPR. However, use of prescription data allowed us to include most ADHD cases not diagnosed in public outpatient clinics. Still, patients with ADHD diagnosed by private psychiatrists but not prescribed medication would be misclassified. It also must be noted that the primary medication used to treat ADHD is methylphenidate, which only has one other rare indication (narcolepsy). Misclassification of ADHD therefore would be non-differential and bias our results towards no association.

In conclusion, the cause of ADHD is multifaceted and may involve risk factors common to ADHD and indications for GC treatment, as well as environmental and genetic factors. Based on our sibling design, prenatal exposure to GCs does not appear to be a risk factor for developing ADHD.

Table 5 Crude and adjusted HRs (aHRs) and 95\% Cls for attention-deficit/hyperactivity disorder (ADHD) in children prenatally exposed to glucocorticoids compared with their unexposed siblings

\section{Children classified with Children not classified ADHD, $n$}

\begin{tabular}{lllll}
\hline Unexposed children & 573 & 705 & 1.00 (Reference) & 1.00 (Reference) \\
Exposed children & 438 & 530 & $1.04(0.90$ to 1.19$)$ & $1.03(0.87$ to 1.20$)$ \\
\hline
\end{tabular}

*Adjusted for birth year (1996-2000, 2001-2005, 2006-2009), sex of the child, birth order, maternal smoking status and maternal infectious diseases during pregnancy. 
Acknowledgements We thank all participants in this study.

Contributors $A B, K L, H T S$ and MSO made primary contributions to writing the manuscript. All authors contributed to the study conception and study design. TF performed data collection, statistical analyses and commented on the manuscript. TF had full access to all the data in the study and takes responsibility for the integrity of the data and the accuracy of the data analyses. All authors contributed to the interpretation of the results, HTS revised the manuscript critically and all approved the final manuscript. HTS is the guarantor for this study.

Funding This work was supported by grants from the Department of Clinical Epidemiology's Research Foundation and the Program for Clinical Research Infrastructure (PROCRIN) established by the Lundbeck Foundation and the Novo Nordisk Foundation. Research was conducted independently of the funder. The Department of Clinical Epidemiology, Aarhus University Hospital, receives funding for other studies from companies in the form of research grants to (and administered by) Aarhus University. None of these studies have any relation to the present study.

Competing interests None declared.

Ethics approval Registry studies do not require ethics approval in Denmark. The study was approved by the Danish Data Protection Agency (Record no 2011-41-6465).

Provenance and peer review Not commissioned; externally peer reviewed.

Data sharing statement № additional data are available.

Open Access This is an Open Access article distributed in accordance with the Creative Commons Attribution Non Commercial (CC BY-NC 4.0) license, which permits others to distribute, remix, adapt, build upon this work non-commercially, and license their derivative works on different terms, provided the original work is properly cited and the use is non-commercial. See: http://creativecommons.org/ licenses/by-nc/4.0/

(c) Article author(s) (or their employer(s) unless otherwise stated in the text of the article) 2017. All rights reserved. No commercial use is permitted unless otherwise expressly granted.

\section{REFERENCES}

1. Hench P. Effects of cortisone in the rheumatic diseases. Lancet 1950;2:483-4.

2. Russell GM, Kalafatakis K, Lightman SL. The importance of biological oscillators for hypothalamic-pituitary-adrenal activity and tissue glucocorticoid response: coordinating stress and neurobehavioural adaptation. J Neuroendocrinol 2015;27:378-88.

3. Buttgereit F, da Silva JA, Boers M, et al. Standardised nomenclature for glucocorticoid dosages and glucocorticoid treatment regimens: current questions and tentative answers in rheumatology. Ann Rheum Dis 2002;61:718-22.

4. Yang K. Placental 11 beta-hydroxysteroid dehydrogenase: barrier to maternal glucocorticoids. Rev Reprod 1997;2:129-32.

5. Wyrwoll CS, Holmes MC. Prenatal excess glucocorticoid exposure and adult affective disorders: a role for serotonergic and catecholamine pathways. Neuroendocrinology 2012;95:47-55.

6. Trautman PD, Meyer-Bahlburg HF, Postelnek J, et al. Effects of early prenatal dexamethasone on the cognitive and behavioral development of young children: results of a pilot study. Psychoneuroendocrinology 1995;20:439-49.

7. Hirvikoski T, Nordenström A, Lindholm T, et al. Cognitive functions in children at risk for congenital adrenal hyperplasia treated prenatally with dexamethasone. J Clin Endocrinol Metab 2007;92:542-8.

8. Welberg LA, Seckl JR, Holmes MC. Prenatal glucocorticoid programming of brain corticosteroid receptors and corticotrophinreleasing hormone: possible implications for behaviour. Neuroscience 2001;104:71-9.
9. Talge NM, Neal C, Glover V, et al. Early Stress, Translational Research and Prevention Science Network: Fetal and Neonatal Experience on Child and Adolescent Mental Health. Antenatal maternal stress and long-term effects on child neurodevelopment: how and why? J Child Psychol Psychiatry 2007;48:245-61.

10. Hocher B. More than genes: the advanced fetal programming hypothesis. J Reprod Immunol 2014;104-105:8-11.

11. Polanczyk G, de Lima MS, Horta BL, et al. The worldwide prevalence of ADHD: a systematic review and metaregression analysis. Am J Psychiatry 2007;164:942-8.

12. Faraone SV, Perlis RH, Doyle AE, et al. Molecular genetics of attention-deficit/hyperactivity disorder. Biol Psychiatry 2005;57:1313-23.

13. Chu SM, Tsai MH, Hwang FM, et al. The relationship between attention deficit hyperactivity disorder and premature infants in Taiwanese: a case control study. BMC Psychiatry 2012;12:85.

14. Polańska K, Jurewicz J, Hanke W. Exposure to environmental and lifestyle factors and attention-deficit / hyperactivity disorder in children - a review of epidemiological studies. Int J Occup Med Environ Health 2012;25:330-55.

15. Swanson JM, Kinsbourne M, Nigg J, et al. Etiologic subtypes of attention-deficit/hyperactivity disorder: brain imaging, molecular genetic and environmental factors and the dopamine hypothesis. Neuropsychol Rev 2007:17:39-59.

16. Linnet KM, Dalsgaard S, Obel C, et al. Maternal lifestyle factors in pregnancy risk of attention deficit hyperactivity disorder and associated behaviors: review of the current evidence. Am J Psychiatry 2003;160:1028-40.

17. Li J, Olsen J, Vestergaard M, et al. Attention-deficit/hyperactivity disorder in the offspring following prenatal maternal bereavement: a nationwide follow-up study in Denmark. Eur Child Adolesc Psychiatry 2010:19:747-53

18. Kapoor A, Petropoulos S, Matthews SG. Fetal programming of hypothalamic-pituitary-adrenal (HPA) axis function and behavior by synthetic glucocorticoids. Brain Res Rev 2008;57:586-95.

19. Van Lieshout RJ, Boyle MH, Saigal S, et al. Mental health of extremely low birth weight survivors in their 30s. Pediatrics 2015;135:452-9.

20. Bröms G, Granath F, Linder M, et al. Birth outcomes in women with inflammatory bowel disease: effects of disease activity and drug exposure. Inflamm Bowel Dis 2014;20:1091-8.

21. Pedersen CB. The Danish Civil Registration System. Scand J Public Health 2011:39:22-5.

22. Knudsen LB, Olsen J. The Danish Medical Birth Registry. Dan Med Bull 1998;45:320-3.

23. Kildemoes HW, Sørensen HT, Hallas J. The Danish National Prescription Registry. Scand J Public Health 2011;39:38-41.

24. definition Trimester, 2016. http://medical-dictionary.thefreedictionary. com/trimester (accessed 14 Nov 2016).

25. Lindström K, Lindblad F, Hjern A. Preterm birth and attentiondeficit/hyperactivity disorder in schoolchildren. Pediatrics 2011;127:858-65.

26. Mors O, Perto GP, Mortensen PB. The Danish Psychiatric Central Research Register. Scand J Public Health 2011:39:54-7.

27. Andersen TF, Madsen M, Jørgensen J, et al. The Danish Nationa Hospital Register. A valuable source of data for modern health sciences. Dan Med Bull 1999;46:263-8.

28. Donovan SJ, Susser E. Commentary: Advent of sibling designs. Int $J$ Epidemiol 2011;40:345-9.

29. Khandaker GM, Zammit S, Lewis G, et al. A population-based study of atopic disorders and inflammatory markers in childhood before psychotic experiences in adolescence. Schizophr Res 2014;152:139-45.

30. Frisell T, Öberg S, Kuja-Halkola R, et al. Sibling comparison designs: bias from non-shared confounders and measurement error. Epidemiology 2012;23:713-20.

31. Sørensen HT, Lash TL, Rothman KJ. Beyond randomized controlled trials: a critical comparison of trials with nonrandomized studies. Hepatology 2006;44:1075-82. 